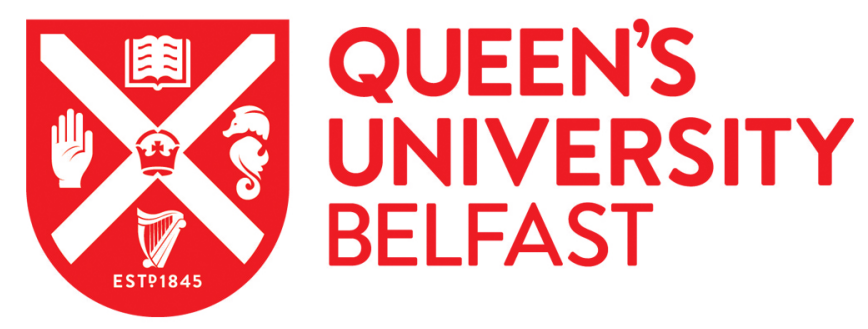

\title{
High speed DSC (hyper-DSC) as a tool to measure the solubility of a drug within a solid or semi-solid matrix
}

Gramaglia, D., Conway, B. R., Kett, V. L., Malcolm, R. K., \& Batchelor, H. K. (2005). High speed DSC (hyperDSC) as a tool to measure the solubility of a drug within a solid or semi-solid matrix. International Journal of Pharmaceutics, 301(1-2), 1-5. https://doi.org/10.1016/j.jpharm.2005.04.038

Published in:

International Journal of Pharmaceutics

Document Version:

Peer reviewed version

Queen's University Belfast - Research Portal:

Link to publication record in Queen's University Belfast Research Portal

Publisher rights

NOTICE: this is the author's version of a work that was accepted for publication in International Journal of Pharmaceutics. Changes resulting from the publishing process, such as peer review, editing, corrections, structural formatting, and other quality control mechanisms may not be reflected in this document. Changes may have been made to this work since it was submitted for publication. A definitive version was subsequently published in International Journal of Pharmaceutics, [VOL 301, ISSUE 1-2, 2005] 10.1016/j.ijpharm.2005.04.038

\section{General rights}

Copyright for the publications made accessible via the Queen's University Belfast Research Portal is retained by the author(s) and / or other copyright owners and it is a condition of accessing these publications that users recognise and abide by the legal requirements associated with these rights.

Take down policy

The Research Portal is Queen's institutional repository that provides access to Queen's research output. Every effort has been made to ensure that content in the Research Portal does not infringe any person's rights, or applicable UK laws. If you discover content in the Research Portal that you believe breaches copyright or violates any law, please contact openaccess@qub.ac.uk. 


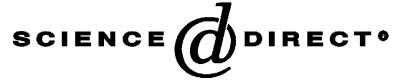

International Journal of Pharmaceutics xxx (2005) xxx-xxx

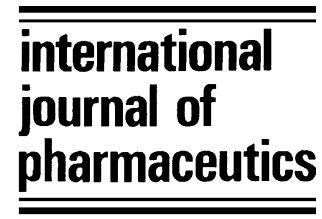

www.elsevier.com/locate/ijpharm

Rapid communication

\title{
High speed DSC (hyper-DSC) as a tool to measure the solubility of a drug within a solid or semi-solid matrix.
}

\author{
Daniela Gramaglia ${ }^{\mathrm{a}}$, Barbara R. Conway ${ }^{\mathrm{b}}$, Vicky L. Kett ${ }^{\mathrm{c}}$, \\ R. Karl Malcolm ${ }^{\mathrm{c}}$, Hannah K. Batchelor ${ }^{b}$,* \\ a Department of Pharmaceutical Chemistry, University of Pavia, Via Taramelli 12, 27100 Pavia, Italy \\ ${ }^{\mathrm{b}}$ Medicines Research Unit, Aston University, Birmingham B4 7ET, UK \\ ' School of Pharmacy, Queen's University of Belfast, 97 Lisburn Road, Belfast BT9 7BL, UK \\ Received 23 September 2004; received in revised form 11 April 2005; accepted 14 April 2005
}

\begin{abstract}
Conventional differential scanning calorimetry (DSC) techniques are commonly used to quantify the solubility of drugs within polymeric-controlled delivery systems. However, the nature of the DSC experiment, and in particular the relatively slow heating rates employed, limit its use to the measurement of drug solubility at the drug's melting temperature. Here, we describe the application of hyper-DSC (HDSC), a variant of DSC involving extremely rapid heating rates, to the calculation of the solubility of a model drug, metronidazole, in silicone elastomer, and demonstrate that the faster heating rates permit the solubility to be calculated under non-equilibrium conditions such that the solubility better approximates that at the temperature of use. At a heating rate of $400{ }^{\circ} \mathrm{C} / \mathrm{min}$ (HDSC), metronidazole solubility was calculated to be $2.16 \mathrm{mg} / \mathrm{g}$ compared with $6.16 \mathrm{mg} / \mathrm{g}$ at $20^{\circ} \mathrm{C} / \mathrm{min}$.

(C) 2005 Elsevier B.V. All rights reserved.
\end{abstract}

Keywords: High-speed DSC; Solubility; Metronidazole; Silicone

\section{Introduction}

The release characteristics of drugs from diffusioncontrolled polymeric delivery systems are largely determined by the solubility and diffusivity of the drug within the cross-linked polymer network (Chien, 1992). However, quantifying the solubility of any sub-

\footnotetext{
* Corresponding author. Tel.: +44 1212043903.

E-mail address: h.k.batchelor@aston.ac.uk (H.K. Batchelor).
}

stance within a polymer network is not straightforward. Simple saturation/filtration solubility studies, as performed for liquid solvents, are clearly not possible, and exhaustive release into a suitable medium will not discriminate between dispersed and dissolved drug (Ahmed et al., 2004). Historically, microscopy has been used to measure solubility within semi-solid or transparent solids with a lack of crystals indicating that all drug present is dissolved. The residual liquid separated from an ointment on storage has been used to 
estimate the solubility of a drug within it (Koboyashi and Saitoh, 1998). X-ray powder diffractometry has been used to measure the solubility of salicylic acid in a hydrogel (Suryanarayanan et al., 1992), whereby the intensities of the salicylic acid peaks in the diffraction trace were linearly related to its weight percent in the formulations, permitting the solubility of the acid in the hydrogel to be estimated from the intercept. However, large degrees of variance were associated with this method (Suryanarayanan et al., 1992). The solubility of a drug in silicone oil has been used as a predictor for solubility within a silicone elastomer matrix (Malcolm et al., 2003a,b, 2004; Woolfson et al., 2003); this method assumes that the solubility characteristics within the relatively low molecular weight oil are similar to those within the cross-linked elastomer. The use of differential scanning calorimetry (DSC) for the quantitative measurement of the solubility of solid drugs dispersed in polymeric matrices was first described by Theeuwes et al. (1974). The method was based on the simple principle that the fraction of drug solubilised within the matrix does not contribute to the melting endotherm associated with the dispersed drug fraction. Thus, by plotting the measured $\Delta H_{\mathrm{f}}$ values versus the drug concentrations for a range of loadings and extrapolating to zero $\Delta H_{\mathrm{f}}$, the solubility of the drug in the polymer could be estimated. However, the use of a relatively slow $10^{\circ} \mathrm{C} / \mathrm{min}$ scanning rate, as is typical for polymeric systems, provides sufficient time for the molecules within the crystal lattice of the drug substance to respond to the input of energy during the heating ramp by detaching from the lattice and further dissolving in the polymer matrix. As a consequence, the solubility value determined is that at the melting temperature of the drug. This DSC method has since been used to determine the solubility of propanolol (Bodmeier and Paeratakal, 1989), salicylic acid and chlorpheniramine (Jenquin and McGinity, 1994), penciclovir (Ahmed et al., 2004), and oxybutynin (Malcolm et al., 2002) in a range of polymer systems. A similar dynamic mechanical method has also been used to estimate drug solubility within silicone elastomer. Changes in storage modulus $\left(\Delta G^{\prime}\right)$ associated with melting of the drug within the silicone matrix were linearly related to drug loading, and extrapolation to zero $\Delta G^{\prime}$ provided an estimate of solubility, once again at the drug's melting point (Malcolm et al., 2002).
Hyper DSC (HDSC) may overcome the disadvantage associated with conventional thermal methods such as DSC and DMTA for determining solubility in polymer systems whereby solubility can only be measured at the drug melting temperature. The fast heating rates do not inhibit the sample from responding to the energy imputed (as seen by no changes in heats of fusion for melt transitions between heating rates) but can affect and inhibit kinetically controlled transitions such as recrystallisation, polymorph interconversion (McGregor et al., 2004); therefore, in this case the high heating rates may inhibit further solubilisation due to the increase in solubility profile caused by increasing the temp that may otherwise occur during slower scans. In order to demonstrate the utility of this approach, this study describes the use of HDSC to measure the solubility of the model drug metronidazole within silicone elastomer.

\section{Materials and methods}

Crystalline metronidazole (M3761) was purchased from Sigma, UK. A two-part, platinum-catalysed silicone elastomer system, Silastic 9280/60E was purchased from Dow Corning, USA.

\subsection{Preparation of the silicone films}

Parts A and B of the silicone elastomer kit were blended in a 1:1 ratio to produce the silicone elastomer mix. Metronidazole was added and mixed $(1,2.5,5,7.5$ and $10 \%, \mathrm{w} / \mathrm{w}$ ) to produce active elastomer mixes. Each mix was then placed between two glass microscope slides separated by 1-mm spacers before curing in a preheated oven at $80^{\circ} \mathrm{C}$ for $24 \mathrm{~h}$ and then at $120^{\circ} \mathrm{C}$ for $1 \mathrm{~h}$. The resulting matrices were refrigerated in airtight containers until required.

\subsection{HDSC experimental protocol}

HDSC experiments were carried out using a diamond DSC (Perkin-Elmer, Pyris series 5.0), calibrated for temperature and enthalpy at each heating rate using an indium standard (Perkin-Elmer). Samples $(4.55 \pm 0.45 \mathrm{mg})$ were cut from the metronidazoleloaded silicone matrices and placed in hermetically 
sealed aluminium pans (Perkin-Elmer); an empty pan was used as a reference in all cases.

Measurements were performed over a temperature range to include the melting temperature of the drug $\left(20-250{ }^{\circ} \mathrm{C}\right)$. Heating rates of 20,100 and $400{ }^{\circ} \mathrm{C} / \mathrm{min}$ were used within the study. Helium was used as the purge gas $(20 \mathrm{~mL} / \mathrm{min})$. The calculation of the area under the transition peak permitted the evaluation of the energy associated with the phase transition, $\Delta H_{\mathrm{f}}$ and so the calculation of solubility. The area under the melting endotherm was calculated from the onset to the end of the peak using the Pyris series 5 data analysis package, (Perkin-Elmer). A blank (non-drugcontaining) silicone film was also measured to ensure that there were no background thermal events. It has already been demonstrated that linear control of heating rate can be achieved at scan rates up to $500^{\circ} \mathrm{C} / \mathrm{min}$ using this equipment (Saunders et al., 2004).

\section{Results and discussion}

The DSC scan of the blank silicone matrix demonstrated a flat baseline with no thermal events over the temperature range investigated. Pure metronidazole demonstrated a melting endotherm at $160^{\circ} \mathrm{C}$ at all scanning rates. The enthalpy of fusion was $163 \pm 3$, $158 \pm 3$ and $162 \pm 5 \mathrm{~J} / \mathrm{g}$ at heating rates of 20,100 and $400^{\circ} \mathrm{C} / \mathrm{min}$, respectively, with no significant difference in this value at all heating rates investigated. However, the size of the endotherm increased dramatically as the scan rate increased, this is because DSC output is measured in $\mathrm{mW}(\mathrm{mJ} / \mathrm{s})$; therefore, faster heating rates increase the size of the power signal due to an alteration in heat capacity $\left(\mathrm{J} /\left(\mathrm{g}{ }^{\circ} \mathrm{C}\right)\right)$. Fig. 1 clearly shows that increasing the heating rate increases the peak magnitude, this trend is similar to that observed by Saunders et al. (2004).

Metronidazole-loaded silicone matrices $(1,2.5,5$, 7.5 and $10 \%, \mathrm{w} / \mathrm{w}$ ) were prepared and investigated at scan rates of 20,100 and $400{ }^{\circ} \mathrm{C} / \mathrm{min}$. Fig. 2 shows the effect of increasing drug concentration on the melting endotherm, with higher concentrations causing the size of the melting endotherm to increase, as it relates to the concentration of undissolved drug present in the formulation at the melting temperature. By plotting $\Delta H_{\mathrm{f}}$ against the drug loading concentration and extrapolating to zero $\Delta H_{\mathrm{f}}$, as in Fig. 3, the solubility of metronidazole in the silicone matrix may be determined. Linear trend lines were fitted using Microsoft Excel with regression values in each case being greater than 0.99 . The solubility values, calculated as the $x$ intercept using these trend lines, were: $0.616 \%(\mathrm{w} / \mathrm{w})$ $\left(20^{\circ} \mathrm{C} / \mathrm{min}\right), 0.493 \%(\mathrm{w} / \mathrm{w})\left(100^{\circ} \mathrm{C} / \mathrm{min}\right)$ and $0.216 \%$ (w/w) $\left(400^{\circ} \mathrm{C} / \mathrm{min}\right)$. Microscopically, the solution process of a drug crystal in a polymer composition can be visualised as consisting of two consecutive steps: (i) the dissociation of drug molecules from the crys-

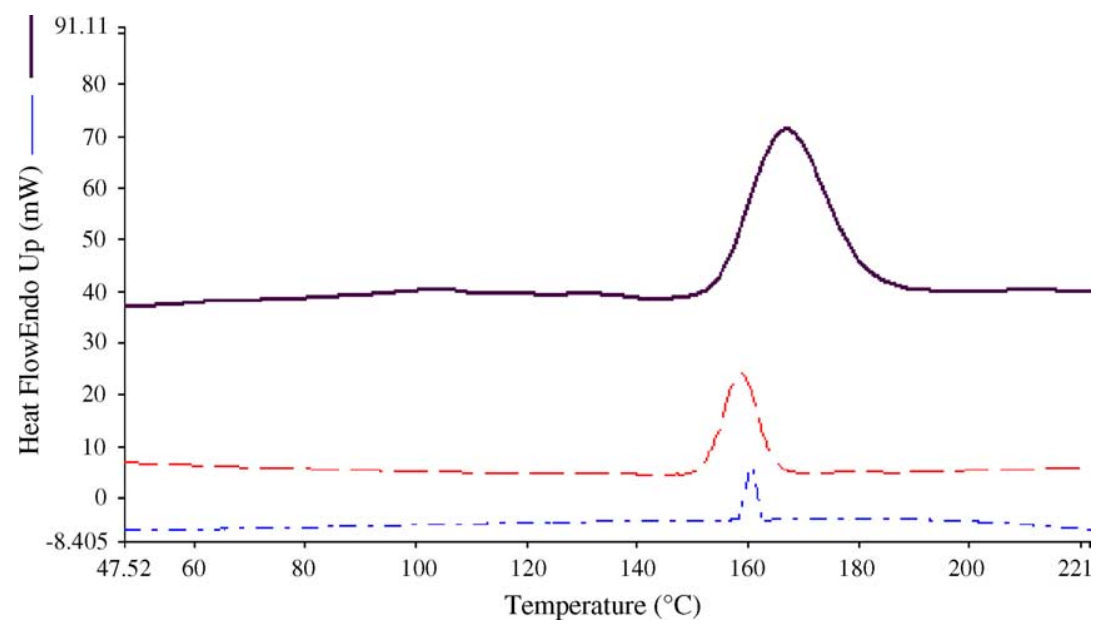

Fig. 1. Typical melting endotherms obseved for metronidazole $(10 \%, \mathrm{w} / \mathrm{w})$ in silicone at heating rates of $20(---), 100(---)$ and $400{ }^{\circ} \mathrm{C} / \mathrm{min}$ (一). 


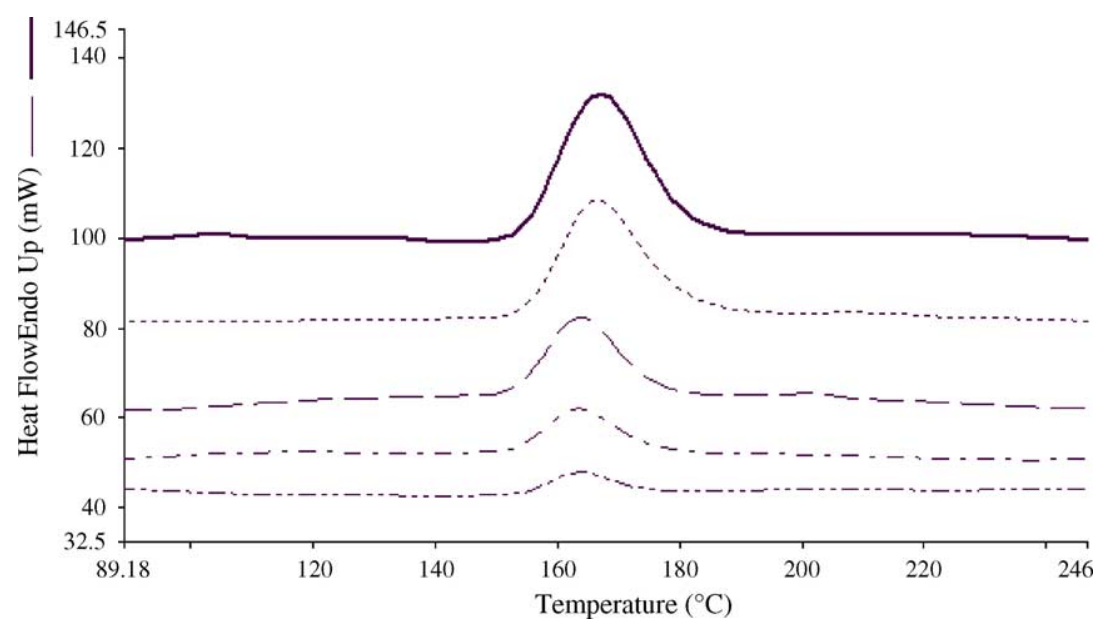

Fig. 2. DSC Data at $400^{\circ} \mathrm{C} / \mathrm{min}$ heating rate of the $1(---), 2.5(---), 5(---), 7.5(--)$ and $10 \%(-)$ (w/w) metronidazole:silicone samples.

tal lattice and (ii) the solvation of these dissociated molecules into the surrounding polymer. Given that the first step is also involved in the melting process, it is apparent that the observed decrease in solubility with increasing heating rate must be largely attributed to the time-dependent solvation process. The faster heating rates provide insufficient time for the drug molecules to dissolve in the polymer. This study shows that the solubility calculated was dependant on the scan rate used, however, the faster the scan rate the better the prediction of solubility as the kinetic events are minimised.

The $0.616 \%(\mathrm{w} / \mathrm{w})$ solubility value for metronidazole in silicone elastomer obtained at $20^{\circ} \mathrm{C} / \mathrm{min}$ using

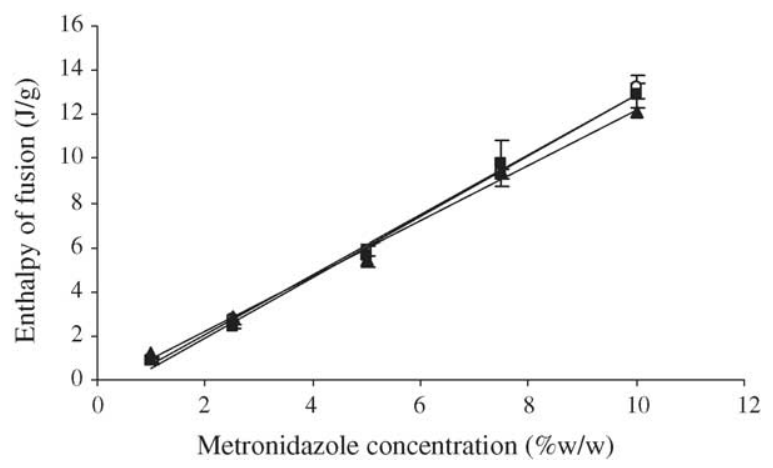

Fig. 3. An example of a plot of metronidazole concentration against the enthalpy of fusion $\left((\bigcirc) 20,(\boldsymbol{\square}) 100\right.$ and $(\boldsymbol{\Delta}) 400^{\circ} \mathrm{C} / \mathrm{min}$ heating rate), $n=4$. conventional DSC is comparable to that calculated previously for the solubility of metronidazole in low viscosity silicone oil $\left(0.006 \mathrm{mg} \mathrm{cm}^{-3}\right.$ or $0.06 \%$, w/w) (Malcolm et al., 2003a,b). However, the former value is likely to overestimate the solubility for the reasons outlined earlier, while the latter value does not take account of the very real physicochemical differences between liquid silicone and silicone elastomer, as discussed in previous studies (Malcolm et al., 2002). The value of $0.216 \%(\mathrm{w} / \mathrm{w})$ obtained by the HDSC method at $400^{\circ} \mathrm{C} / \mathrm{min}$ is a more realistic estimate in that it is measured in silicone elastomer under conditions that serve to minimize the effects of temperature on solubility.

\section{Conclusions}

This study has shown that hyper DSC offers a simple, fast and effective way to measure the solubility of a drug within a solid polymer matrix. Faster heating rates reduce further dissolution of drug into the matrix with heating and thus a more realistic estimation of silicone solubility at working temperature is provided. In this case a solubility of $0.216 \%(\mathrm{w} / \mathrm{w})$ metronidazole in silicone was predicted using HDSC. Solubility prediction is dependant upon the scan rate used, the high speed DSC enables data to be collected at higher heating rates with no loss in quality of data, thus fast scan rates should be used where possible. 


\section{Acknowledgement}

The authors would like to thank the Socrates/ Erasmus exchange programme that enabled Daniela Gramaglia's study stay at Aston University.

\section{References}

Ahmed, A., Barry, B.W., Williams, A.C., Davis, A.F., 2004. Penciclovir solubility in Eudragit films: a comparison of X-ray, thermal, microscopic and release rate techniques. J. Pharm. Biochem. Anal. 34, 945-956.

Bodmeier, R., Paeratakal, O., 1989. Evaluation of drug-containing polymer films prepared from aqueous latexes. Pharm. Res. 6, 723-730.

Chien, Y.W., 1992. Novel drug delivery systems. Drugs and the Pharmaceutical Sciences, vol. 50, second ed. Marcel Dekker, Inc., New York, pp. 3-12 (Chapter 1).

Jenquin, M.R., McGinity, J.W., 1994. Characterization of acrylic resin matrix films and mechanisms of drug-polymer interactions. Int. J. Pharm. 101, 23-34.

Koboyashi, N., Saitoh, I., 1998. A method to measure the solubility of drugs in ointment bases. Chem. Pharm. Bull. 46, 1833-1835.

Malcolm, R.K., McCullagh, S., Woolfson, A.D., Catney, M., Tallon, P., 2002. A dynamic mechanical method for determining the silicone elastomer solubility of drugs and pharmaceutical excipients in silicone intravaginal drug delivery rings. Biomaterials 23 , 3589-3594.
Malcolm, R.K., Woolfson, A.D., Russell, J., Tallon, P., McAuley, L., Craig, D.Q.M., 2003a. Influence of silicone elastomer solubility and diffusivity on the in vitro release of drugs from intravaginal rings. J. Control. Release 90, 217-225.

Malcolm, R.K., Woolfson, A.D., Russell, J., Andrews, C., 2003b. In vitro release of nonoxynol-9 from silicone matrix intravaginal rings. J. Control. Release 91, 355-364.

Malcolm, R.K., McCullagh, S.D., Woolfson, A.D., Gorman, S.P., Jones, D.S., Cuddy, J., 2004. Controlled release of a model antibacterial drug from a novel self-lubricating silicone biomaterial. J. Control. Release 97, 313-320.

McGregor, C., Saunders, M.H., Buckton, G., Saklatvala, R.D., 2004. The use of high-speed differential scanning calorimetry (hyperDSCTM) to study the thermal properties of carbamazepine polymorphs. Thermochim. Acta 417, 231-237.

Saunders, M.H., Podluii, K., Shergill, S., Buckton, G., Royall, P.G., 2004. The potential of high speed DSC (hyper-DSC) for the detection and quantification of small amounts of amorphous content in predominantly crystalline samples. Int. J. Pharm. 274, 35-40.

Suryanarayanan, R., Venkatesh, S., Hodgin, L., Hanson, P., 1992. Determination of the physical state of salicylic acid in hydrogel formulations by X-ray diffractometry. Int. J. Pharm. 78, 7783.

Theeuwes, F., Hussain, A., Higuchi, T., 1974. Quantitative analytical method for determination of drugs dispersed in polymers using differential scanning calorimetry. J. Pharm. Sci. 63, 427-429.

Woolfson, A.D., Malcolm, R.K., Gallagher, R.J., 2003. Design of a silicone reservoir intravaginal ring for the delivery of oxybutynin. J. Control. Release 91, 465-476. 